\title{
APPLICATION OF PROJECT CASH MANAGEMENT AND CONTROL FOR INFRASTRUCTURE
}

\section{Cheng-Wu Chen}

Institute of Maritime Information and Technology, National Kaohsiung Marine University, Kaohsiung City 80543,

Taiwan, R.O.C., chengwu@mail.nkmu.edu.tw

Morris Hsiao-Lung Wang

Department of Tourism and Leisure Management, Vanung University, Chung-li, Taiwan, R.O.C

Kevin Fong-Re Liu

Department of Safety, Health and Environmental Engineering, Ming Chi University of Technology, Taipei, Taiwan, R.O.C

Tsung-Hao Chen

Department of Administration Management, Shu-Te University, Kaohsiung 82445, Taiwan, R.O.C

Follow this and additional works at: https://jmstt.ntou.edu.tw/journal

Part of the Business Commons

\section{Recommended Citation}

Chen, Cheng-Wu; Wang, Morris Hsiao-Lung; Liu, Kevin Fong-Re; and Chen, Tsung-Hao (2010) "APPLICATION OF PROJECT CASH MANAGEMENT AND CONTROL FOR INFRASTRUCTURE," Journal of Marine Science and Technology. Vol. 18: Iss. 5, Article 3.

DOI: $10.51400 / 2709-6998.1902$

Available at: https://jmstt.ntou.edu.tw/journal/vol18/iss5/3

This Research Article is brought to you for free and open access by Journal of Marine Science and Technology. It has been accepted for inclusion in Journal of Marine Science and Technology by an authorized editor of Journal of Marine Science and Technology. 


\section{APPLICATION OF PROJECT CASH MANAGEMENT AND CONTROL FOR}

INFRASTRUCTURE

\section{Acknowledgements}

The authors would like to thank the National Science Council of the Republic of China, Taiwan, for their financial support of this research under Contract Nos. NSC 98-2221- E-153-004, NSC

98-2221-E-366-006-MY2 and NSC 96-2628- E-366-004-MY2. The authors are also most grateful for the kind assistance of Prof. Chee-Fai Yung, Editor of JMST, and the constructive suggestions of the anonymous reviewers all of which has led to the making of several corrections and suggestions that have greatly aided us in the presentation of this paper 


\title{
APPLICATION OF PROJECT CASH MANAGEMENT AND CONTROL FOR INFRASTRUCTURE
}

\author{
Cheng-Wu Chen*, Morris Hsiao-Lung Wang**, Kevin Fong-Rey Liu***, \\ and Tsung-Hao Chen****
}

Key words: infrastructure project, cash management and control, target cash balance.

\begin{abstract}
In this study we look at infrastructure tender projects. Financial data for cost estimates are collected from 42 infrastructure tender projects (including 20 MRT construction tender projects, 14 highway construction tender projects, and 8 public building tender projects). The Takagi-Sugeno's fuzzy theory is first applied to build an s-curve regression model for big projects. After the model is fitted, the cash-to-cash cycle concept is applied to analyze and diagram cash flow estimations for the execution stage of contracted projects. The goal is to understand short-term financial demands that occur during the execution stage, which leads to a better understanding of cash flow problems. Then, by revising the Miller-Orr cash flow model, a flexible target cash balance model with dual control limits is developed. The analysis of the model application is simple. All the calculations can be done with a trial balance software package such as Excel. In practice, contractors can use s-curve models to preview the cash distribution and amount demanded before projects are executed. Once construction is under way, data from the actual project cash flow can be used to update and revise the predictions. Preparation for dispatching of funds will be made according to cash predictions from the models.
\end{abstract}

\section{INTRODUCTION}

Construction management involves many problems, such

Paper submitted 05/30/08; revised 08/27/09; accepted 08/31/09. Author for correspondence: Cheng-Wu Chen (e-mail: chengwu@mail.nkmu.edu.tw). *Institute of Maritime Information and Technology, National Kaohsiung Marine University, Kaohsiung City 80543, Taiwan, R.O.C.

**Department of Tourism and Leisure Management, Vanung University, Chung-li, Taiwan, R.O.C.

***Department of Safety, Health and Environmental Engineering, Ming Chi University of Technology, Taipei, Taiwan, R.O.C.

****Department of Administration Management, Shu-Te University, Kaohsiung 82445, Taiwan, R.O.C. as cash control, engineering technique, and manpower management and so on [21]. This paper will focus on the cash management and control for infrastructures. General contractors play a prominent role in the construction industry supply chain, having the flexibility that allows them to respond to a variety of construction needs demanded by the demand chain. Public owners, private property developers, banking institutions and shareholders of business entities are directly or indirectly involved in the demand chain. There is typically a superfluous supply of construction companies with similar backgrounds and capabilities on the market. Under these conditions, players involved in the demand chain must carefully evaluate the background of a prospective general contractor before entering into a contract with them.

For many years, the construction industry has had a higher bankruptcy ratio than other industries [22]. One of the critical causes lies in the improper utilization of cash resources. Therefore, prediction of expected cash demands at the tender stage is an extremely important issue for any contractor. According to one related study, problems with cash flow during the initial period of implementation of an engineering project as well as poor control performance were the primary causes which could lead to a financial crisis in the construction industry [14]. In addition, when competition is high, the contractor not only has to work under a smaller profit margin, but also assume greater risks resulting from uncertainties during the construction period. Being able to predict project cash flows while satisfying the contractor's demands, and, at the same time, estimating the impact of various risk factors should help the contractor improve their financial condition. Reliable cash estimation for the construction plan can ensure that cash demands are met with.

Prior to the further study of an engineering project's cash flow, we first need to understand the cost framework for the entire construction plan. Generally speaking, the total amount needed for a project contract includes the total construction costs and profits, and the total construction costs, which is comprised of engineering expenses and management fees (including the administrative fees shared by the head office, the interest on working capital, Value-added Tax, and so on). Of 
these, engineering expenses are mainly comprised of both direct and indirect costs, wherein the direct costs include expenses for materials and machinery, labor (manpower) charges, sub-contracting fees, etc. Direct costs refer to direct expenses for the project during the execution stage. The amount for expenses is usually generated from calculations of both the quantity and unit price needed for the projected construction. The indirect costs comprise the worksite management fees needed for maintaining the construction project, engineering expenses, and so on. Although these presumed engineering expenses, which support the operation of direct engineering, are not directly entered into the execution of construction, they are indispensable for accomplishing the project.

Peer [29] computed the cumulative curve for total cost and total time in order to predict cash flows for public construction projects from historical data. Kaka and Price [24] constructed a cost conversion curve based on historical case data for purchasing expenses, and then combined this with an income curve to calculate cash flows. Navon [28] modified the cash flow prediction model, based on the S-curve polynomials of study cases. They examined the difference between the predicted value and the actual value. They tried to enhance the value of the model for practical applications by making the predicted value closer to the actual value.

Insufficient cash flow in the initial stage of construction is a critical factor in a company's failure. It is therefore necessary to simplify the estimation procedure for minimum working capital (MWC) during the contract execution period for a quicker calculation. Hassim et al. [14] proposed a simple model for estimating the correlation between MWC and various relevant factors. The model was then applied to a housing constructing project in Malaysia. This model met the MWC requirements for the contractor during the contract execution period.

Hwee and Tiong [22] developed a set of cash flow prediction models for application to the construction industry, which emphasized the importance of pre-understanding the cash flows and the influence of various risk factors. Their cash flow forecasting system was a kind of computer-based model that could analyze the influence of five risk factors upon the project cash flow, taking into account variation in construction time, material costs, risk measurement risk variation, etc. The results from practical engineering testing, in which tests were continuously performed on the influence of cash flow and construction results caused by these five factors during the duration of the construction showed that even though the amount of data required to be input into this model was very simple, it still provided a rather accurate assessment of cash requirements.

S-curves are helpful tools for project management in that they can accurately show current project status, and predict future progress [13]. They are already widely used in industry for project management [27, 32, 34].

Cash flow is one of the most important sources of information in financial analysis. It can clearly show the net amount

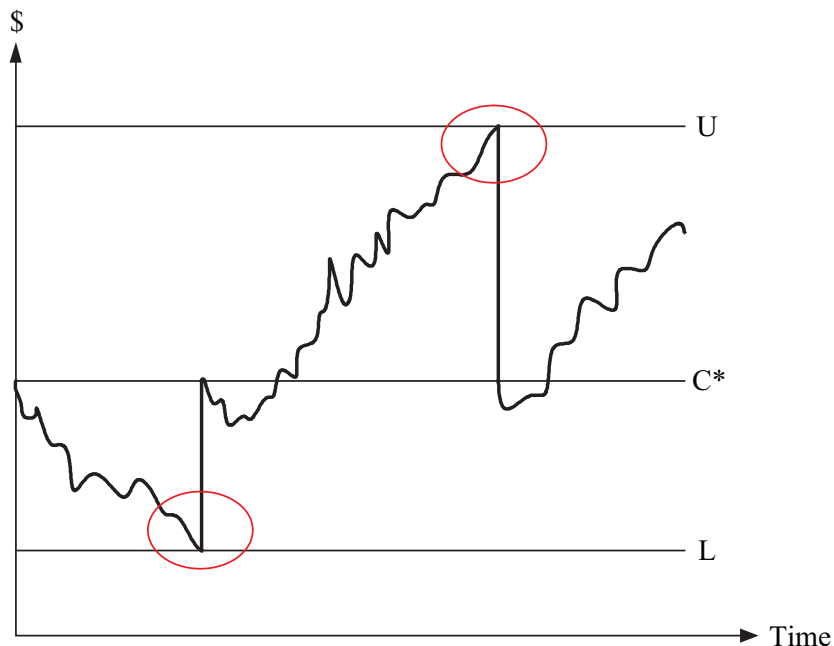

Fig. 1. Miller-Orr cash management model.

of cash available for a company. Therefore, if analysis and prediction of cash flow can be performed before construction on a project begins it helps to understand cash demands during the construction stage in advance. Finance and fund dispatching plans can be made earlier to avoid situations of insufficient cash turnover.

In this study, Takagi-Sugeno's fuzzy theory is first applied to build an s-curve regression model. Based upon TakagiSugeno's fuzzy concepts, a practical s-curve regression model is fitted to the sample data. Then, using this s-curve regression model, and the cash-to-cash cycle concept, a cash flow diagram is obtained generated from the cash expenses of the sample tenders.

This is followed by the building of a model for cash management and control. The model is based on the Miller-Orr model, referencing the cash flow impulse control model of Bar Ilan et al. [1]. The sample data are tested and used to derive a revised Miller-Orr model for analysis. After this the variance in the cash flow is calculated, the transaction cost and opportunity cost set up, and the target cash balance (TCB) calculated. Finally, the model is evaluated and put into use (including the predictions of cash flow amount and cash balance) and some conclusions are obtained.

\section{CASH MANAGEMENT MODEL}

The popular Miller-Orr model can be used to help construction firms maintain a balance, as illustrated in Fig. 1 [23, 31]. The model argues that adjustment for irregular cash flow follows patterns that occur at various times and is best handled through the use of dual control limits. In other words, a firm sets its cash limits based upon both operating characteristics and credit conditions. The upper cash limit $\mathrm{U}$ and target cash balance $C^{*}$ can be set based on transaction costs, variance of cash flow and the opportunity cost of holding cash. Once the upper and lower thresholds have been identified, a firm can 


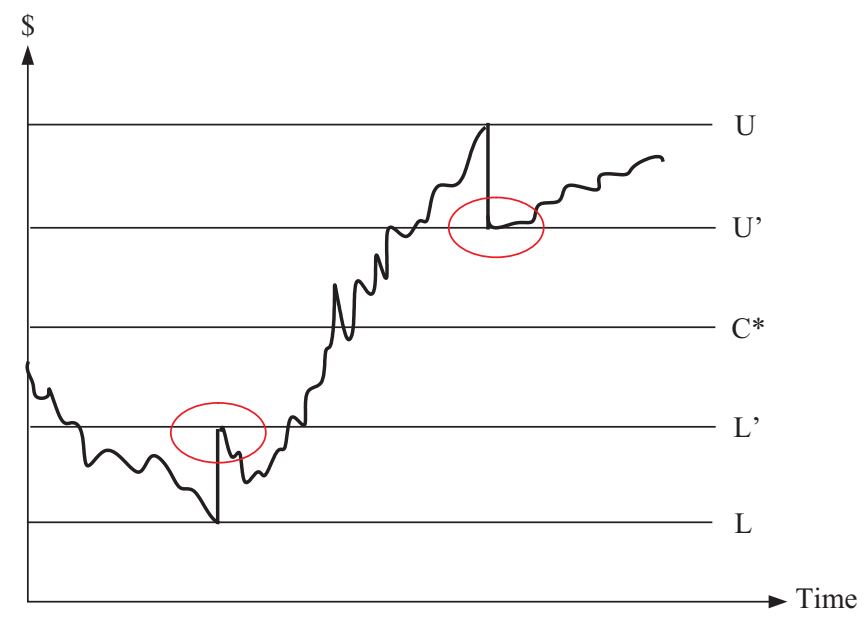

Fig. 2. Impulse control cash management model.

determine their own best timing for investing cash in marketable securities or trading notes for cash. The Miller-Orr model simplifies the task of working capital management by finding the target cash balance and the associated limits.

Bar-Ilan et al. [1] derived a cash management model from the Miller-Orr model, which is designed to manage the problem of random impulse control with a cash discount. In this method, the cash flows are described by Brownian motion resulting from positive and negative wave motions. The cash flows can be kept on track by means of the impulse control policy (ICB), meaning that the controlling personnel could raise or lower the current quantity of cash at any time. The ICB of the jump-diffusion model can easily control cash flow in practical applications. The cash flows within this model achieve effective control by means of targets and limits at both ends, as shown in Fig. 2, wherein, the horizontal axis represents time, and vertical axis represents the cash balance (cash flows).

The advantages of a cash management model with an impulse control function lie in a deceleration of the volatility of the cash flows. The modeling helps to relieve both the quantity and pressure of the capital allocation on the management personnel. This model is very suitable for application to the construction industry and its business characteristics. Contractors in the construction industry do not usually have sufficient self-owned capital. They therefore prefer short-term financing, and often have less working capital as reserves for engineering turnover. Under these circumstances if the volatility of cash flow during the execution of the projected construction can be decreased, and both the quantity and pressure of the capital allocation relieved, this will definitely facilitate control of project cash flows leading to improvement of costs and earnings as well.

\section{CHARACTERISTICS OF THE SAMPLE DATA}

Table 1. Statistics for sample project tenders (collected for this study.).

\begin{tabular}{|l|r|r|r|c|}
\hline & All Samples & MRT Samples & Road Samples & $\begin{array}{c}\text { Infrastructure } \\
\text { Sample }\end{array}$ \\
\hline Average & $1,152,622,255$ & $1,709,517,284$ & $906,429,976$ & $99,947,672$ \\
\hline Max & $5,344,703,689$ & $5,344,703,689$ & $2,245,000,000$ & $188,120,490$ \\
\hline Min & $56,466,920$ & $99,836,177$ & $90,700,000$ & $56,466,920$ \\
\hline
\end{tabular}

Table 2. Statistics for project duration.

\begin{tabular}{|l|c|c|c|c|}
\hline & All Samples & MRT Samples & Road Samples & $\begin{array}{c}\text { Infrastructure } \\
\text { Sample }\end{array}$ \\
\hline Average & 58 & 78 & 51 & 22 \\
\hline Max & 97 & 97 & 68 & 35 \\
\hline Min & 11 & 41 & 20 & 11 \\
\hline
\end{tabular}

Cost estimate data from 42 infrastructure project tenders, including 20 MRT construction project tenders, 14 highway construction project tenders, and 8 public building project tenders, were collected for cash flow analysis and the building of the cash flow model. The sample was selected from projects with amounts exceeding the construction and property purchase amount for supervision set up by the Public Construction Commission under the Executive Yuan, currently NT\$50,000,000, covering the period from 1984 to 2001. The average tender scale was 1.15 billion NT dollars, and the average project duration 58 months, as shown in Tables 1-2.

\section{FUZZY S-CURVE AND PROJECT CASH MANAGEMENT}

The T-S fuzzy model was developed by Takagi and Sugeno [33] to represent nonlinear relationships among multiple input and output data based on fuzzy reasoning. The resulting overall fuzzy regression model, which is usually nonlinear, is achieved via the fuzzy blending of each individual inputoutput realization [2-5, 7-12, 15-19, 25, 26, 30, 35, 37-39]. Financial data for cost estimate from 39 infrastructure tender projects were collected for sample for this study. Regression analysis was performed with Takagi-Sugeno's fuzzy theory. We obtained the following regression model $[6,20]$ (see Fig. 3): $C=-12.93 T^{6}+42.07 T^{5}-49.49 T^{4}+23.07 T^{3}-1.98 T^{2}+$ $0.25 T$, where $C$ denotes the complete percentage (\%); and $T$ is the duration time $(\%)$.

Next, the amount of the project cash flow is calculated with the s-curve formula, and substituted into the cash flow model. Cash balance management and control is achieved by analyzing and calculating the information needed for the project, such as the demand for equity funds. This can be used as a reference to help contractors with their decision making.

In this study, cost data provided by the BES Engineering 


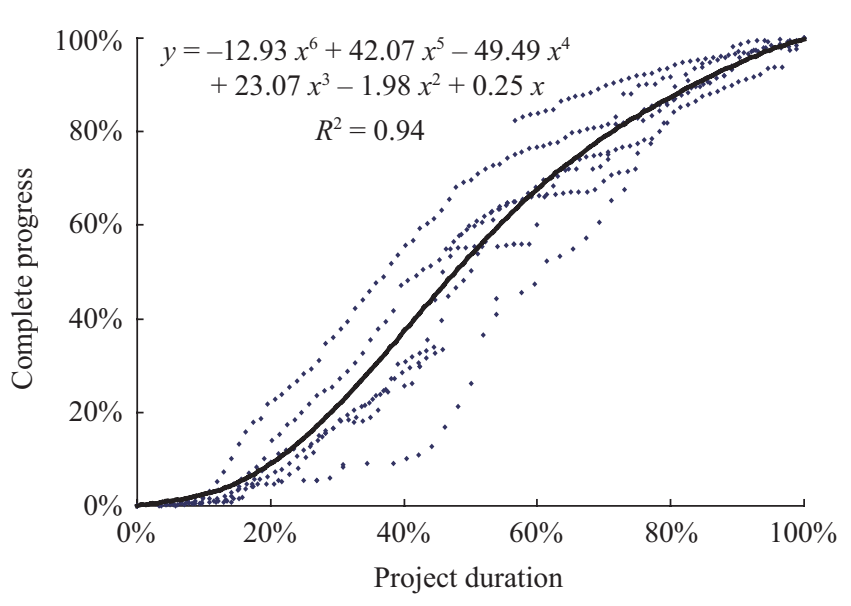

Fig. 3. S-curve from the fuzzy regression method.

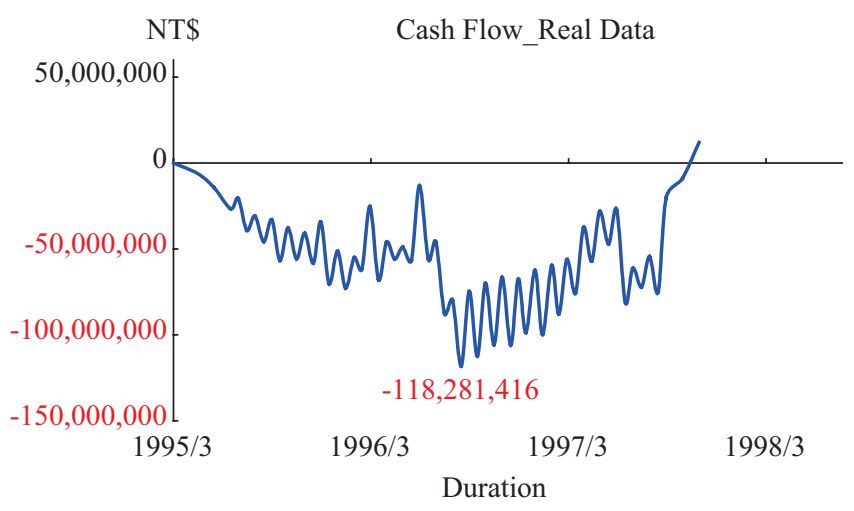

Fig. 4. Cash flow diagram (actual amounts).

Corporation from 1997 are used for validation. (Data source: Baoshan Engineering Office, BES Engineering Corporation. Project name: East-West Expressway, Nanliao-Jhudong Line Construction. Construction scale: NT\$950,000,000. Period covered: March, 1995 to November, 1997. The construction had not been completed by that time.)

The actual cost data and cost estimate payment records were obtained from proprietors. The data were combined to calculate the cash flow amount for the project. As can be seen in Fig. 4, the lowest point in the cash flow diagram $(-118,281,416)$ occurred in August 1996. The project cash flow amounts, which were obtained from the costs calculated from the contractors' cash income with the cash-to-cash cycle, were used as contrast. As can be seen in Fig. 5, the lowest point in the cash flow diagram also occurred in August 1996. The time is the same and the amount is close (error: 5.6\%). Furthermore, because the lowest point of the latter is lower than the actual data (meaning the fund demanded is larger), it means that contractors' demands for funds were not underestimated, and there would be no problems with the financial conditions.

The two diagrams matches were overlapped for comparison. It was concluded that they match each other closely. The solid

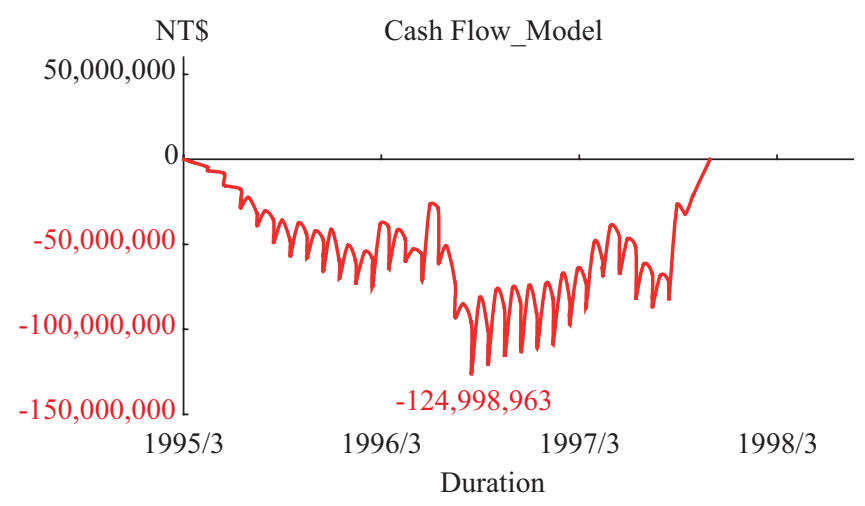

Fig. 5. Cash flow diagram (amounts calculated with the cash-to-cash cycle model).

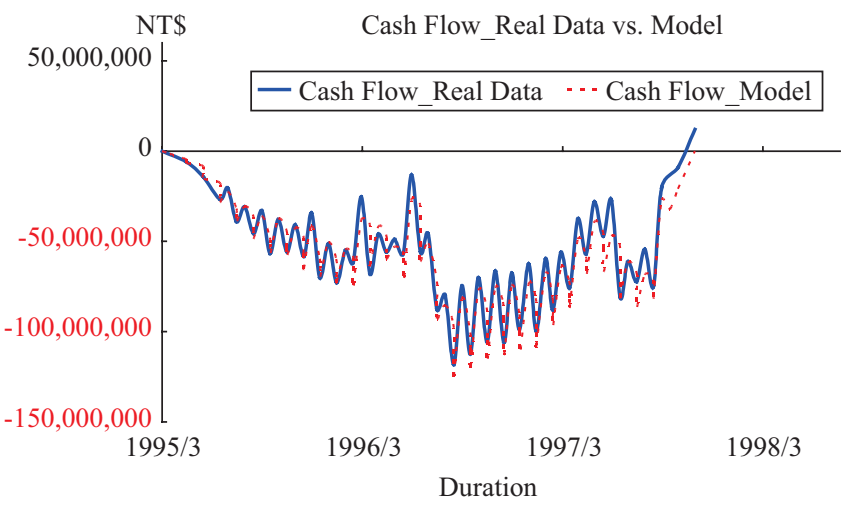

Fig. 6. Cash flow diagram (actual amounts vs. cash-to-cash cycle).

line in Fig. 6 represents the actual cash flow amount, while the dotted line represents the amount of cash flow estimated by the model. It is slightly lower than the actual amount. The result shows that the cash flow amount calculated with the cashto-cash cycle model does match the actual amount quite well. The validation result also supports the correctness of the first research hypothesis.

The differences between the actual amounts and those obtained from the cash control model were further probed in order to verify the correctness of the research hypothesis. Figure 7 shows the fluctuation of the actual cash balance: TCB $=10.69 \%(\mathrm{NT} \$ 101,587,061)$. During the construction stage, the cash balance reached the lower control limit three times and it was necessary to borrow funds. The three times were: September 1995 (NT\$29,595,969); July 1996 (NT\$30,959,844); and August 1996 (NT\$30,682,072). The cash balance also reached the upper control limit twice and it was necessary to pay debts to lower the water-line of funds in: May 1997 (NT\$35,997,986); and November 1997 (NT\$40,201,577). Figure 8 shows the fluctuation of the cash balance calculated with the cash-to-cash cycle model: TCB = $10.66 \%$ (NT\$101,282,150). During the construction stage, the cash balance also reached the control lower limit three times and it was necessary to borrow funds in: September 1995 


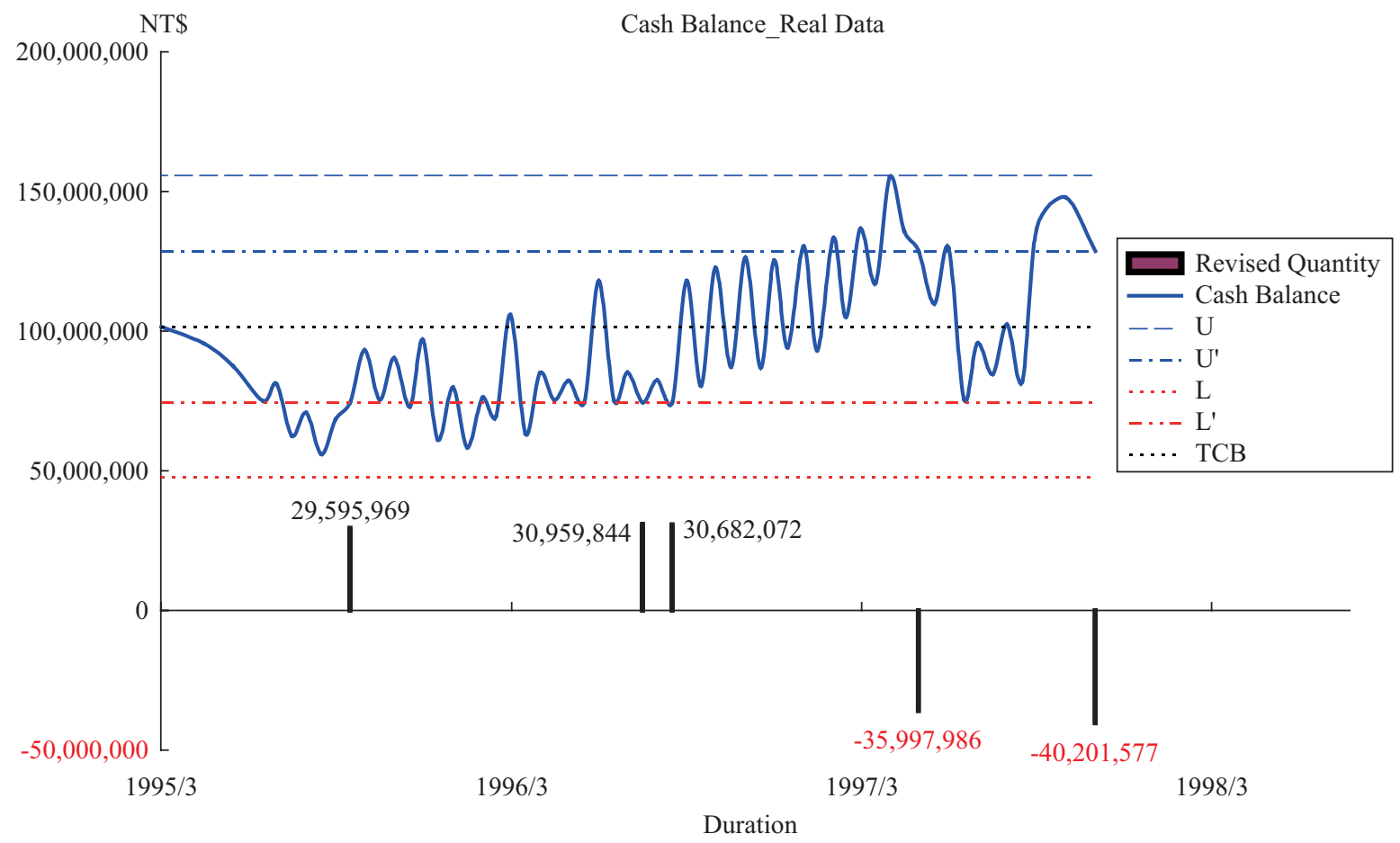

Fig. 7. Cash balance diagram (actual amounts).

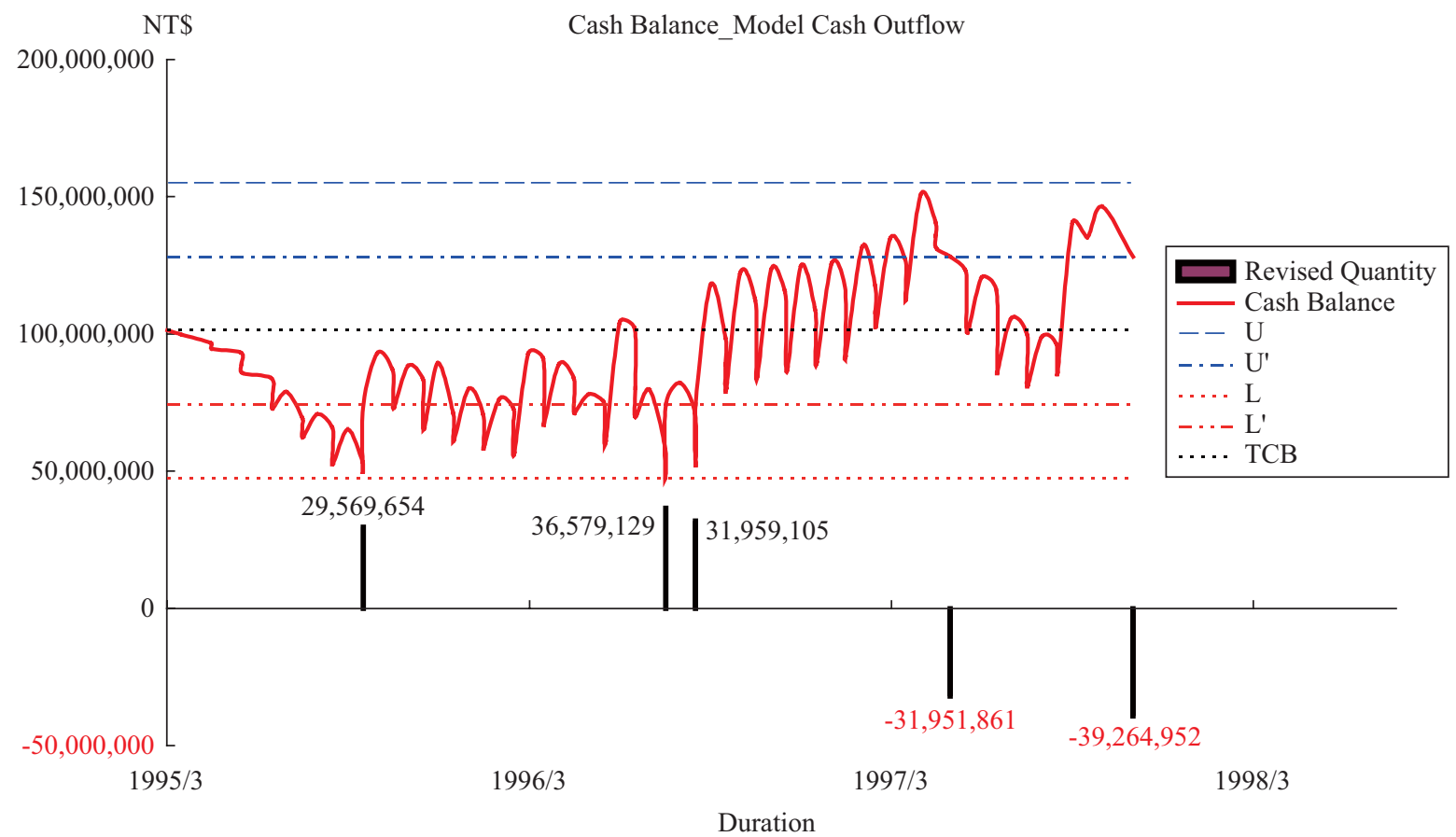

Fig. 8. Cash balance diagram (cash-to-cash cycle calculated amounts).

(NT\$29,569,654); July 1996 (NT\$36,579,129); and August 1996 (NT\$31,959,105). The cash balance reached the upper control limit twice and it was necessary to pay debts to lower the water-line of funds in: May 1997 (NT\$31,961,861); and November 1997 (NT\$39,264,952). A comparison of Figs. 7 and 8 shows that not only are the TCB amounts close to the actual amounts, but the five time points where fund dispatching was required are completely the same. The results support the correctness of the first research hypothesis.

According to the real-case analysis of the sample tender 


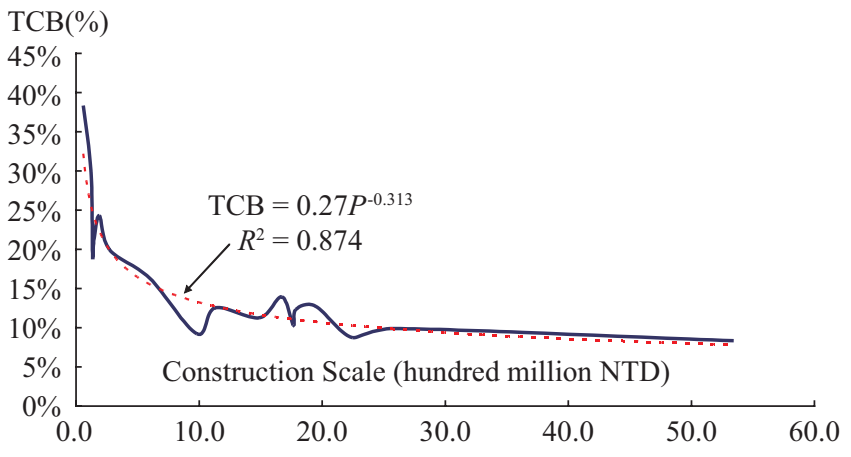

Fig. 9. Association between TCB and construction scale.

projects in this study, the average TCB is $16.4 \%$ of the corresponding tender scale. The TCB is $16.22 \%$ for tender projects without prepayments and $16.65 \%$ for tender projects with prepayments. Although the average TCB for tender projects with prepayments is higher than that of tender projects without prepayments, one thing worth noticing is that the average prepayment amount is $16.66 \%$, which is close to the actual TCB amount required. In other words, proprietors have already prepared the equity funds required by contractors when making advances. Generally speaking, there is an inverse relation between the TCB amount and the scale of each tender project. For tender projects over one billion NT dollars in scale, the trend is for the TCB amount to get smoother and steadier. For tenders below one billion NT dollars in scale, the trend is for the TCB amount to climb rapidly. This means the model developed in this study is more suitable for big tender projects. As shown in Fig. 9 (solid line), the amounts can be represented by the regression equation $\left(\mathrm{TCB}=0.27 P^{-0.313}\right.$, where $P$ is the project scale amount). Contractors can reference the results of this correlation analysis when tendering construction projects. This regression equation can be used to roughly estimate the funds required for projects, as a reference for tender planning and contract execution. This is designed to help contractors with their project cash management and control, and improve their profits. When putting this method into practice, both the companies' cash access and their financial strategy should be taken into account.

\section{CONCLUSIONS AND SUGGESTIONS FOR FUTURE RESEARCH}

In practice, before submitting tenders, contractors can utilize this model to preview the distribution of cash flow and the amount of equity required for the projects, as reference for earlier-on decision making as to whether to submit tenders or not. If contractors believe projects are worth tendering for, manpower and material resources can be plugged in prior to further preparation work for appraising and tendering, to save on costs of related operations. Afterwards, if the contractor receives the contract, this model can be applied to assist with project cash control and management. Furthermore during the construction stage, the actual cash flow amount can be used to make further adjustments, so that preparation for dispatching of funds can be made in advance. The model validation results show that there is a box shaped fluctuation between the upper and lower limits. On average, there are only 1 or 2 chances for borrowing of funds each year. The pressure of financial management which occurs when projects are underway can be reduced by appropriate money management.

The traditional way to prepare for a tender is by mobilizing manpower and material resources. The preparation for appraisal for tender projects can lead to considerable accumulation and consumption of routine costs. The model developed in this study can be used to preview fund-related requirements. Reference information can be obtained from earlier decision making. The method helps to significantly lower the costs mentioned above which improves the contractor's competitiveness. During the construction stage, contractors can utilize the model to assist with cash flow management and control. Data on amount of cash flow can be continuously updated to efficiently manage and control fluctuation of the project cash balance. The calculations can be easily carried out by any general trial balance software. If this model could be integrated into a company's ERP systems, combined with information from all company departments, it could provide even more efficient and timely information as reference for management decision making.

The set lower limits for the control balance control model should be set depending on each company's financial condition and strategies. The higher the credit ranking possessed by the company, the lower the value of the lower limit set. The same setting condition can be applied to a company with an aggressive financial strategy. On the other hand, for a company that has neither an aggressive financial strategy nor a good credit ranking (making it harder to obtain a bank loan) the lower limit should be moved upward. In this way, a business crisis due to lack of instant financial support due to the shortage of working capital should be avoidable.

The greater the cash flow variation $\left(\sigma^{2}\right)$, the higher the target cash balance will be. This may result in a higher than expected penalty fee (increased interest rate and compensating balance), resulting in increased construction cost so should be executed from the standpoint of resource allocation. Average planning of construction scheduling can be utilized to decrease variation, thus reducing funding costs, and increasing earnings. The variation in cash flow is positively related to sample size. In other words, the larger the scale of a tender, the greater the variation in the cash flow will be, meaning that the difficulty of schedule management and control increase along with the construction scale. Both capital requirements and costs increase, which, along with variation, affects profitability. This circumstance will ultimately create an unfavorable result in regards to the execution of projected construction. Observation of the allocation of cash flow showed that there was usually dramatic change in cash flow in the tenders for MRT construction projects in the middle of the construction period. 
This indicated possible massive expenditure when entering into an intensive stage of the construction. Various resources were also put into construction at this stage. In accordance with the preceding analysis, carelessness or lack of attention by the management department could easily lead to increased costs and waste of the resources. However, the allocation of cash flow for the highway construction tenders and for public building project were relatively more diffuse and gentle.

Generally speaking, for construction projects such as an MRT projects, which are characterized by a long construction period, large construction scale and investment value, higher level of difficulty, and so on, the contractor should carefully evaluate whether its company is large enough in scale to manage this particular project, and whether its credit resources are sufficient for the allocation of the required capital, or it should cooperate with other companies on a joint venture for this project (joint venture within or across the industry). The equalization of the resources and construction scheduling referred to in the preceding paragraphs helps find problems related to interface integration and coordination. It can help to prevent problems derived from this type of interface that can affect the project progress, as well as preset financial planning and allocation, hence creating financial crisis in the company.

\section{ACKNOWLEDGMENTS}

The authors would like to thank the National Science Council of the Republic of China, Taiwan, for their financial support of this research under Contract Nos. NSC 98-2221E-153-004, NSC 98-2221-E-366-006-MY2 and NSC 96-2628E-366-004-MY2. The authors are also most grateful for the kind assistance of Prof. Chee-Fai Yung, Editor of JMST, and the constructive suggestions of the anonymous reviewers all of which has led to the making of several corrections and suggestions that have greatly aided us in the presentation of this paper.

\section{REFERENCES}

1. Bar-Ilan, A., Perry, D., and Stadje, W., "A generalized impulse control model of cash management," Journal of Economic Dynamics and Control, Vol. 28, No. 6, pp. 1013-1034 (2004).

2. Benrejeb, M., Sakly, A., Ben, O. K., and Borne, P., "Choice of conjunctive operator of TSK fuzzy systems and stability domain study" Mathematics and Computers in Simulation, Vol. 76, pp. 410-421 (2008).

3. Chen, C. W., "Modeling and control for nonlinear structural systems via a NN-based approach," Expert Systems with Applications, Vol. 36, No. 3, pp. 4765-4772 (2009).

4. Chen, C. W., "The stability of an oceanic structure with T-S fuzzy models," Mathematics and Computers in Simulation, Vol. 80, No. 2, pp. $402-$ 426 (2009).

5. Chen, C. W., Lin, C. L., Tsai, C. H., Chen, C. Y., and Yeh, K., "A novel delay-dependent criteria for time-delay T-S fuzzy systems using fuzzy Lyapunov method," International Journal on Artificial Intelligence Tools, Vol. 16, No. 3, pp. 545-552 (2007).

6. Chen, C. W., Morris, H., Wang, L., and Lin, J. W., "Managing target the cash balance in construction firms using a fuzzy regression approach," International Journal of Uncertainty, Fuzziness and Knowledge-Based
Systems, Vol. 17, No. 5, pp. 667-684 (2009).

7. Chen, C. W., Shen, C. W., Chen, C. Y., and Cheng, M. J., "Stability analysis of an oceanic structure using the Lyapunov method," Engineering Computations, Vol. 27, No. 2, pp. 186-204 (2010).

8. Chen, C. W., Yeh, K., Chiang, W. L., Chen, C. Y., and Wu, D. J., "Modeling, $\mathrm{H}^{\infty}$ control and stability analysis for structural systems using Takagi-Sugeno fuzzy model," Journal of Vibration and Control, Vol. 13, No. 11, pp. 1519-1534 (2007).

9. Chen, C. Y., Hsu, R. C., and Chen, C. W., "Fuzzy logic derivation of neural network models with time delays in subsystems," International Journal on Artificial Intelligence Tools, Vol. 14, No. 6, pp. 967-974 (2005).

10. Chen, C. Y., Shen, C. W., Chen, C. W., and Cheng, M. J., "A stability criterion for time-delay tension leg platform systems subjected to external force," China Ocean Engineering, Vol. 23, No. 1, pp. $49-57$ (2009).

11. Chuang, C. C., Jeng, J. T., and Tao, C. W., "Hybrid robust approach for TSK fuzzy modeling with outliers," Expert Systems with Applications, Vol. 36, pp. 8925-8931 (2009).

12. Chung, H. Y. and Wu, S. M., "Hybrid approaches for regional TakagiSugeno static output feedback fuzzy controller design," E Expert Systems with Applications, Vol. 36, pp. 1720-1730 (2009).

13. Halpin, D. W. and Woodhead, R. W., Construction Management, New York, Wiley (1998).

14. Hassim, S., Kadir, M. R. A., Lew, Y. L., and Sim, Y. C., "Estimation of minimum working capital for construction projects in Malaysia," Journal of Construction Engineering and Management, Vol. 129, No. 4, pp. 369374 (2003).

15. Hsiao, F. H., Chen, C. W., Liang, Y. W., Xu, S. D., and Chiang, W. L., "T-S fuzzy controllers for nonlinear interconnected systems with multiple time delays," IEEE Transactions on Circuits \& Systems-I: Regular Papers, Vol. 52, No. 9, pp. 1883-1893 (2005).

16. Hsiao, F. H., Chen, C. W., Wu, Y. H., and Chiang, W. L., "Fuzzy controllers for nonlinear interconnected TMD systems with external force," Journal of the Chinese Institute of Engineers, Vol. 28, No. 1, pp. 175-181 (2005).

17. Hsiao, F. H., Chiang, W. L., Chen, C. W., Xu, S. D., and Wu, S. L., "Application and robustness design of fuzzy controller for resonant and chaotic systems with external disturbance," International Journal of Uncertainty, Fuzziness and Knowledge-Based System, Vol. 13, No. 3, pp. 281-295 (2005).

18. Hsiao, F. H., Hwang, J. D., Chen, C. W., and Tsai, Z. R., "Robust stabilization of nonlinear multiple time-delay large-scale systems via decentralized fuzzy control," IEEE Transactions on Fuzzy Systems, Vol. 13, No. 1, pp. 152-163 (2005).

19. Hsieh, T. Y., Wang, H. L., Chen C. W., Chen, C. Y., Yu, S. E., Yang, H. C., and Chen, T. H., "A new viewpoint of s-curve regression model and its application to construction management," International Journal on Artificial Intelligence Tools, Vol. 15, pp. 131-142 (2006).

20. Hsieh, T. Y., Wang, H. L., and Chen, C. W., "A case study of s-curve regression method to project control of construction management via T-S fuzzy model," Journal of Marine Science and Technology, Vol. 12, No. 3, pp. 209-216 (2004).

21. Huang, R. Y., Huang, C. T., Lin, H., and Ku, W. H., "Factor analysis of interface problems among construction parties-A case study of MRT," Journal of Marine Science and Technology, Vol. 16, No. 1, pp. 52-63 (2008).

22. Hwee, N. G. and Tiong, R. L. K., "Model on cash flow forecasting and risk analysis for contracting firms," International Journal of Project Management, Vol. 20, pp. 351-363 (2002).

23. Juang, J. L., "The research on working capital investment," Journal Nan-Tai College Bullet, Vol. 20, pp. $93-97$ (1994).

24. Kaka, A. P., "Contractors' financial budgeting using computer simulation," Construction Management and Economics, Vol. 12, pp. 113-124 (1994).

25. Lin, M. L. and Chen, C. W., "Application of fuzzy models for the monitoring of ecologically sensitive ecosystems in a dynamic semi-arid landscape from satellite imagery," Engineering Computations, Vol. 27, No. 1, 
pp. 5-19 (2010).

26. Lin, M. L., Chen, C. W., Wang, Q. B., Cao, Y., Shih, J. Y., Lee, Y. T., Chen, C. Y., and Wang, S., "Fuzzy model-based assessment and monitoring of desertification using MODIS satellite imagery," Engineering Computations, Vol. 26, No. 7, pp. 745-760 (2009).

27. Miskawi, Z., "An S-curve equation for project control," Construction Management and Economics, Vol. 7, pp. 115-124 (1989).

28. Navon, R., "Company-level cash-flow management," Journal of Construction Engineering and Management, ASCE, Vol. 122, pp. 22-29 (1996)

29. Peer, S., "Application of cost-flow forecasting models" Journal of Construction Division, June ASCE, Vol. 108, No. 2, pp. 226-232 (1982).

30. Pereira, R. A. M., Ribeiro, R. A., and Serra, P., "Rule correlation and choquet integration in fuzzy inference systems," International Journal of Uncertainty, Fuzziness and Knowledge-Based Systems, Vol. 16, No. 5 , pp. 601-626 (2008)

31. Ross, S. A., Westerfield, R. W., and Jordan, B. D., Fundamentals of Corporate Finance, Richard D. Irwin Inc., New York (1995).

32. Rudolf, E., "The S-curve relation between per-capita income and insurance penetration," Geneva Papers on Risk \& Insurance - Issues \& Practice, Vol. 25, pp. 396-406 (2000).
33. Takagi, T. and Sugeno, M., "Fuzzy identification of systems and its applications to modeling and control," IEEE Transactions on Systems, Man, Cybernetics, Vol. 15, 116-132 (1985).

34. Tribble, R. Jr., "A restatement of the s-curve hypothesis," Review of Development Economics, Vol. 3, pp. 207-214 (1999).

35. Tsai, C. H., Chen, C. W., Chiang, W. L., and Lin, M. L., "Application of geographic information system to the allocation of disaster shelters via fuzzy models," Engineering Computations, Vol. 25, No. 1, pp. 86-100 (2008).

36. Wang, H. O., Tanaka, K., and Griffin, M. F., “An approach to fuzzy control of nonlinear systems: Stability and design issues," IEEE Transactions on Fuzzy Systems, Vol. 4, pp. 14-23 (1996).

37. Yeh, K., Chen, C. Y., and Chen, C. W., "Robustness design of time-delay fuzzy systems using fuzzy Lyapunov method," Applied Mathematics and Computation, Vol. 205, No. 2, pp. 568-577 (2008).

38. Yu, F. M., "The compact fuzzy filter design via Takagi-Sugeno fuzzy models," Expert Systems with Applications, Vol. 36, pp. $4412-4416$ (2009).

39. Zhong, Q. S., Bao, J. F., Yu, Y. B., and Liao, X., "Impulsive control for T-S fuzzy model-based chaotic systems," Mathematics and Computers in Simulation, Vol. 79, No. 3, pp. 410-421 (2008). 